\title{
Are risk-based dental recalls risky?
}

\author{
Derek Richards \\ Editor
}

The routine six-month dental recall has a long history in dentistry. In an editorial in $2002^{1}$ I highlighted that it was Pierre Fauchard in the $18^{\text {th }}$ century who first proposed regular dental examinations, although he suggested visiting 2-3 times per year.

'Those who are diligent on the conservation of their teeth and who wish to avoid being the victim of their error or their negligence ought to have them examined two or three times every year by an experienced dentist ...' 2

The idea that regular dental checkups should take place every six months was probably popularised by American advertisers of dental products in the 1930s and it has remained a popular mantra ever since. It was not until 1977 that the evidence-base underlying the exhortation to visit the dentist every six months was challenged by Aubrey Sheiham in his Lancet paper. ${ }^{3}$

However, it was almost 30 years later before the first systematic review on the question was conducted by Davenport et al. ${ }^{4}$ Although the review included 28 studies, many were cross-sectional and often poorly reported. The authors concluded; 'There is no existing highquality evidence to support or refute the practice of encouraging six-monthly dental checks in adults and children.'

The Davenport review was updated as part of the process for the NICE (National Institute for Health and Care Excellence) guideline on Dental Recall published in $2004^{5}$ and subsequently a Cochrane review was published in $2005 .^{6}$ The Cochrane review was updated in 2007 and 2013. ${ }^{7}$ While the Cochrane review has been updated it only includes one randomised controlled trial, ${ }^{8}$ and that trial was considered to be at high risk of bias. As a result, the review continued with the conclusion that there was insufficient evidence to support or refute the practice of sixmonthly recalls.

Since the initial publication of the NICE guideline in $2004^{5}$ it has been formally reviewed on a number of occasions - 2018 being the most recent - after which they indicated that they found no new evidence that affects the recommendations in this guideline. Nevertheless, the guidelines were grounded on best practice and expert opinion derived using formal and informal consensus methods.

The key NICE recommendation is that:

'The recommended interval between oral health reviews should be determined specifically for each patient and tailored to meet his or her needs, on the basis of an assessment of disease levels and risk of or from dental disease. '

NICE also recommended the following shortest and longest intervals between one assessment and the next assessment:

- The shortest interval for all patients is three months

- The longest interval for patients younger than 18 years is 12 months

- The longest interval for patients aged 18 years and older is 24 months.
This was important and a significant move away from what had become 'routine practice' and has been interpreted in some quarters that all adults should move from six monthly recalls to 24 month recalls. A blanket move for all patients was never the intention of the Guidance panel as it was recommended that the recall interval be regularly discussed and agreed based on their oral health risk profile and amended up or down accordingly.

In 2011 the Scottish Dental Clinical Effectiveness Programme (SDCEP) published their guidance on oral health assessment and review which was based on the NICE recommendations. ${ }^{9}$ In this context it is interesting to look at the Scottish experience as the six-monthly check remains part of the Statement of Dental Remuneration as it has for decades, and since 2006 the dental checkup for adults has been free. Data from the Information Services Division ${ }^{10}$ show that the vast majority of Scottish adults did not attend NHS primary care dental services on an annual basis, with only $23 \%$ attending at least once per year in each of the previous six years, with $21 \%$ not attending any year in the past six years, and with the remaining population attending over a range of annual attendance patterns over the same period (Fig. 1).

A scale and polish is a regular element of many a dental check, however it is worth noting the conclusions from the recent IQuaD trial. ${ }^{11}$ This was a pragmatic primary care-based trial conducted in multiple practices across the UK. The trial compared personalised oral health advice (OHA) versus routine OHA, 12-monthly S\&P (scale and polish) compared with six-monthly $S \& P$, and no $S \& P$ compared with six-monthly S\&P. The key finding being that there was no additional clinical benefit from scheduling six-monthly or 12-monthly scale and polish.

Even in patients requiring periodontal maintenance, evidence from a 2015 systematic review ${ }^{12}$ that included eight cohort studies did not find evidence to support a specific recall interval for all patients following periodontal therapy.

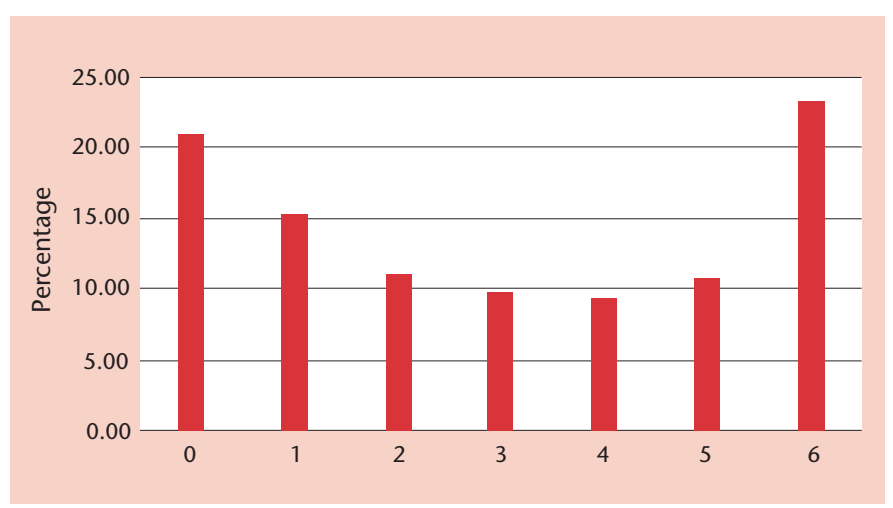

Figure1. Percentage of $18+$ adults attending at least once per year in any one year between 2012-2018 


\section{Oral cancer and dental recall}

One of the persistent arguments from the profession in relation to the dental check-up is that in moving away from regular sixmonthly check ups dentists will miss the opportunity to pick up patients with mouth cancer. A recent paper in the British Dental Journal highlighted incidence of oral cavity cancer in the UK. ${ }^{13}$ The rates were highest in Scotland at 10.0 per 100,000 for males followed by 5.9 per 100,000 in Northern Ireland, 7.4 per 100,000 in Wales and 7.3/100,000 in England.

Another BDJ paper by Brocklehurst and Speight ${ }^{14}$ discussed the pros and cons of a national oral cancer screening programme, clearly pointing out that currently mouth cancer screening only satisfied five out of 20 of the criteria required by the UK National Screening Committee. Even where the criteria have been addressed, they have only been partially met, while the majority of the other criteria have not been considered, so more research is needed. Although there is a need to address all the criteria an important issue is the limited understanding of the early natural history of the disease, particularly in relation to the role and progression of oral potentially malignant lesions.

While it is important that dental examination includes the soft tissues of the mouth to identify malignant or potentially malignant lesions, detecting oral cancer may not be a realistic option, as another $B D J$ paper from Purkayastha et al. ${ }^{15}$ points out. The Purkayastha et al. study was a large population-database data-linkage conducted in Scotland, which demonstrated that in Scotland a dentist might expect to encounter one case of oral cancer every ten years. It also found that $53.7 \%$ of oral cancer patients had no dental contact in the two years prior to their diagnosis, which decreases the opportunity for early detection.

For oral squamous cell carcinoma two of the most important risk factors are tobacco and alcohol use, and potentially the dentists' and dental teams' most important role in reducing oral cancer rates is asking about alcohol and tobacco use and advising patients to stop smoking and reduce their alcohol consumption. However, it is fair to say that the current NHS dental contracts do not fully specify nor fund the time required to deliver brief prevention interventions.

To address the question I posed in my title I have discussed some key reviews, guidelines and papers on this topic. The available evidence does not provide any real support for a fixed time interval for all patients to visit the dentist, let alone a fixed interval of six months. The NICE guidance represents one of the best summaries of the available evidence and recommends individual risk intervals based on a personalised assessment of their risk which for adults could vary between three to 24 months at any given point in a patient's life course. More research is needed in relation to the prevention, care, treatment and monitoring of patients' oral health to ensure patients oral health status is maintained to a high standard. For the recall interval in particular the results of another pragmatic primary care based study, the INTERVAL (investigation of NICE technologies for enabling risk-variable-adjusted-length) dental recalls trial ${ }^{16}$ are expected to be in the public domain next year. Hopefully this will provide additional high quality information to assess the risk-based recall.

\section{Acknowledgements}

The author would like to thank Jan Clarkson and David Conway for their helpful comments on an earlier draft of this editorial.

\section{Note}

The author was a member of the NICE Guideline Development Group on Dental Recall and is a member of the SDCEP guidance development group on Oral Health Assessment.

\section{References}

1. Richards D. The six-monthly dental check. Evid Based Dent 2002; 3: 61.

2. Fauchard P. The Surgeon Dentist or Treatise on the Teeth (1746). Vol II. Translation. London: Butterworth, 1946:4.

3. Sheiham A. Is there a scientific basis for six-monthly dental examinations? Lancet 1977; 2: 442-444. PubMed PMID: 70653.

4. Davenport C, Elley K, Salas C, et al. The clinical effectiveness and cost-effectiveness of routine dental checks: a systematic review and economic evaluation. Health Technol Assess 2003; 7: 1-127.

5. National Collaborating Centre for Acute Care (UK). Dental Recall: Recall Interval Between Routine Dental Examinations. London: National Collaborating Centre for Acute Care (UK); 2004 Oct. PubMed PMID: 21678631.

6. Beirne P, Forgie A, Clarkson J, Worthington HV. Recall intervals for oral health in primary care patients. Cochrane Database Syst Rev 2005; 2: Art. No.: CD004346 DOI: 10.1002/14651858.CD004346.pub2.

7. Riley P, Worthington HV, Clarkson JE, Beirne PV. Recall intervals for oral health in primary care patients. Cochrane Database Syst Rev 2013; 12: Art. No.: CD004346. DOI: 10.1002/14651858.CD004346.pub4.

8. Wang N, Marstrander P, Holst D, Ovrum L, Dahle T. Extending recall intervals - effect on resource consumption and dental health. Community Dent Oral Epidemiol 1992; 20: $122-124$.

9. Oral Health Assessment and Review: Dental Clinical Guidance. Scottish Dental Clinical Effectiveness Programme (2012) Available at http://www.sdcep.org.uk/ published-guidance/oral-health-assessment/ (accessed December 2018).

10. ISD Dental Team. NHS Scotland. Annual primary care dental attendance (2012 2018). Personal communication - D.Conway.

11. Ramsay CR, Clarkson JE, Duncan A, et al. Improving the Quality of Dentistry (IQuaD): a cluster factorial randomised controlled trial comparing the effectiveness and costbenefit of oral hygiene advice and/or periodontal instrumentation with routine care for the prevention and management of periodontal disease in dentate adults attending dental primary care. Health Technol Assess 2018; 22:1-144. doi: 10.3310/ hta22380. PubMed PMID: 29984691; PubMed Central PMCID: PMC6055082.

12. Faroogi OA, Wehler CJ, Gibson G, Jurasic MM, Jones JA. Appropriate Recall Interval for Periodontal Maintenance: A Systematic Review. J Evid Based Dent Pract 2015; 15: 171-181. doi: 10.1016/j.jebdp.2015.10.001. Epub 2015 Nov 19. Review. Erratum in: J Evid Based Dent Pract 2016; 16: 79. PubMed PMID:26698003; PubMed Central PMCID: PMC4848042.

13. Conway DI, Purkayastha M, Chestnutt IG. The changing epidemiology of oral cancer: definitions, trends, and risk factors. Br Dent / 2018; 225: 867-873. doi: 10.1038/ sj.bdj.2018.922. PubMed PMID: 30412558

14. Brocklehurst PR, Speight PM. Screening for mouth cancer: the pros and cons of a national programme. Br Dent / 2018; 225: 815-819. doi: 10.1038/sj.bdj.2018.918. PubMed PMID: 30412550.

15. Purkayastha M, McMahon AD, Gibson J, Conway DI. Is detecting oral cancer in general dental practices a realistic expectation? A population-based study using population linked data in Scotland. Br Dent / 2018; 225: 241-246. doi: 10.1038/ sj.bdj.2018.544. PubMed PMID: 30095121.

16. Clarkson JE, Pitts NB, Bonetti D, et al.; INTERVAL Trial Collaboration. INTERVAL (investigation of NICE technologies for enabling risk-variable-adjusted-length) dental recalls trial: a multicentre randomised controlled trial investigating the best dental recall interval for optimum, cost-effective maintenance of oral health in dentate adults attending dental primary care. BMC Oral Health 2018; 18: 135. doi: 10.1186/s12903-018-0587-2. PubMed PMID: 30086747; PubMed Central PMCID: PMC6081817.

Evidence-Based Dentistry (2018) 19, 98-99. doi:10.1038/sj.ebd.6401353 